\title{
Studying anatomy through a problem-based learning approach
}

\begin{abstract}
Introduction: The problem-based learning is a pedagogical method that seeks to optimize the acquisition of knowledge by taking into account, in particular, principles derived from acquired knowledge in cognitive psychology. We wanted to assess feelings of our students about this approach in anatomy.

Materials and methods: Eighty-three undergraduate students took part in the survey. Various activities to introduce problem-based learning in anatomy included lectures, workshops, and demonstrations of mannequins and other composite parts. For each problem, students were divided into small groups to facilitate the use of knowledge gained in anatomy, the discussion and the reasoning. They had time to manage and were evaluated at the end of this learning. An opinion questionnaire was then given to the students to obtain their opinion concerning this teaching method. Students' degree of agreement was measured according to the Likert scale.
\end{abstract}

Results: The behavior of students during this problem-based approach has been very positive in anatomy. For $92 \%$ of them, the approach based on problem-based learning in anatomy is a stimulating and intuitive method, even if conventional teaching (lectures) remains unavoidable.

Conclusion: The pedagogical experience that we report for a fundamental discipline is limited. However, it testifies to the good receptivity of students in anatomy for the problem-based learning.

Keywords: problem-based learning, anatomy, pedagogy
Volume 4 Issue 5 - 2017

\author{
Philippe Manyacka MA Nyemb $b^{1,2}$ \\ 'Laboratory of Anatomy and Organogenesis, Gaston Berger \\ University, Sénégal \\ ${ }^{2}$ General Surgery Service, Regional Hospital, Sénégal
}

\begin{abstract}
Correspondence: Philippe Manyacka MA Nyemb, Laboratory of Anatomy and Organogenesis, UFR 2S, Gaston Berger University, Road of Ngallèlle, 234 Saint-Louis, Sénégal, Tel (+22I) 7744543 13, Email phil_manyacka@yahoo.fr
\end{abstract}

Received: November 13, 2017| Published: December 18, 2017

\section{Introduction}

Reforming traditional anatomy by linking it to clinical practice has great benefits for learning. The application of anatomical principles in the explanation of clinical signs and therapeutic procedures enhances the motivation of students to learn anatomy. As a result of this reform, problem-based learning $(\mathrm{PBL})$ is a pedagogical method that appeared a few decades ago. ${ }^{1}$ It is used not only during pre-doctoral medical studies, but also more and more early in the medical curriculum. In the Faculty of Medicine of Saint-Louis, Senegal, the adaptation of students to this new teaching method is progressively made in anatomy. The introduction of problem-based learning in a curriculum offers teachers and students another approach to anatomical pedagogy. ${ }^{2}$ This method offers a more modern approach to the teaching of anatomy, more fulfilling for the student because it is directly related to clinical approach.

After introducing the problem-based learning method into the anatomy curriculum, and after the students become familiar with this new technique, the authors of this paper collected first- and secondyear medical students' impressions, in the Faculty of Medicine of The Gaston Berger University in Saint-Louis.

\section{Materials and methods}

Eighty-three undergraduate students took part in the survey. These 83 students represented the entire number of student in first and second years of the medical curriculum. The abstention rate was 0 . The survey was conducted at the end of the annual anatomy teaching. Various activities to introduce problem-based learning in anatomy included lectures, workshops, and demonstrations on models and composite specimens. For each problem, students were divided into small groups of 5-6 students, to facilitate the use of knowledge acquired in anatomy, the discussion and the reasoning. They had a 20 to 25 minutes time to manage, and were evaluated at the end of this learning. An anonymous opinion questionnaire containing 8 proposals was then given to the students in order to obtain their opinion concerning this teaching method. Students' degree of agreement was measured according to the Likert scale in five values.

\section{Results}

For most of them, students positively welcomed the problembased learning approach in anatomy. For $92 \%$ of them, the approach concerning problem-based learning in anatomy is a stimulating and intuitive method, even if the conventional teaching (lectures, practical work) remains unavoidable according to the comments of the students. Most students favorably noted the study of anatomy by this method. The more detailed results are shown in Table 1.

In the space reserved for comments, students insisted on the need to vary teaching methods and to introduce more interactive methods. Comments also show that students value teaching methods that emphasize the clinical aspect of medicine. However, it is clear from the remarks that classical teaching cannot be replaced by any of these methods.

\section{Discussion}

Problem-based learning was initiated at the Mc Master University in 1965. ${ }^{1}$ Problem-based learning is defined as a learning (or teaching) method that focuses on solving real or hypothetical problems and 
clinical cases in small groups of students. ${ }^{1}$ Students take an active role in their learning. Problem-based learning focuses more on the understanding of the clinical case presented than on blind reproduction and memorization. This innovative approach allows better understanding and memorization of facts and principles. In the case of the problem-based learning, teachers have a fundamentally different role, consisting more in listening to and guiding the group's work than in speaking and distributing pedagogical information.

The PBL method can be used to introduce students to the pedagogical basics, learning strategies and therapeutic principles during their medical studies. This new way of teaching initiated a small revolution in the medical training community, and has spread around the world. However, this method has been adopted in various ways. Some medical schools have completely changed their curriculum to the profile of problem-based learning. ${ }^{3}$ Other schools (such as Saint-Louis Faculty of medicine) have partially integrated problem-based learning into their conventional teaching. ${ }^{4,5}$ Despite many studies showing the benefits of problem-based learning, ${ }^{6}$ there is still debate about whether problem-based learning can effectively replace traditional pedagogy. ${ }^{1}$ In Saint-Louis we think that it should not replace conventional teaching, but rather complete it. Anatomy remains one of the most impenetrable disciplines in the introduction of problem-based learning.

In practice, students review anatomy in small clinical case discussion groups. The clinical cases are presented in each group, followed by a discussion. Group discussion allows students to develop clinical thinking and problem-solving skills that are fundamental to medical practice. They learn to search for sources of information, and to work as a team. The teacher assesses students' progress on the basis of building their knowledge, problem-solving skills, and developing interpersonal relationships. ${ }^{1}$

Problem-based learning (PBL) is a pedagogical method widely used in pre-doctoral medical studies. In the Faculty of Medicine of Saint-Louis in Senegal, the initiation of students to the PBL through masterful presentations has recently been initiated. The introduction of problem-based learning in a faculty curriculum creates a new institutional challenge that makes it necessary to establish a basic socio-educational culture through training programs for both teachers and students. An introduction to the PBL methodology and the pedagogical concepts that underlie it is necessary for students who will begin to apply this method of learning during their medical studies. Different activities of introducing students to new learning methods include lectures, workshops, video presentations and demonstrations. Students who participated in problem-based learning sessions benefited from small group work and active learning: they used their previous knowledge, discussed, developed and organized the instructional concepts they had to acquire. They also benefited from autonomous learning with a managed work time, individual work and a final assessment of their learning. The behavior of students about work around a problem has been very positive.

The Faculty of Medicine of the Gaston Berger University in Saint-Louis encourages in-depth learning of anatomy by diversifying teaching methods. To promote the learning depth of our students, we offer them a preclinical medical curriculum based mainly on problembased learning (PBL) as teaching and learning formats. These parallel methods complete the basic teaching of anatomy provided during lectures and practical work in the laboratory. ${ }^{7}$ In order to verify if our approach produces the expected results, we decided to assess our students' perception of this method of learning. Student perception was assessed using a questionnaire using a Likert scale. The questionnaire was designed around 8 proposals related to the benefits of the problem-based learning approach. Although other questionnaires were developed from works of Marton and Säljö, Entwistle and Ramsden and those of many other authors, ${ }^{8}$ we wanted to simplify our questionnaire for this first experiment. Of 83 students in the study, 82 found that problem-based learning in anatomy was a stimulating method. For 81 students, the group discussions were informative and the learning objectives were clear. For 80 students the reference used during the exercise was adequate. The teaching concepts were assimilated for 78 students, and 74 students found sufficient time for the exercise. For 74 students, the method and the clinical cases used were a good introduction to problem-based learning. Moreover, for 72 students out of 83, a problem-based learning session in anatomy had become familiar following the exercise.

The clinical anatomy lesson serves as a bridge between basic anatomy and the clinician's profession. In a problem-based learning curriculum, students must be able to integrate basic and clinical science, evidence-based decision-making, clinical reasoning, and psychomotor skills. In the problem-based learning approach, students expect to be evaluated more by the application of reasoning processes than by pure memorization of facts. The evaluation of anatomy learning in the problem-based approach requires the use of several methods. Because no evaluation method can test all three aspects of learning: knowledge, attitudes, and skills., ${ }^{910}$ The teaching system and assessment methods should encourage anatomy teachers to formulate clinically oriented questionnaires, as this contributes to the popularization of anatomy learning through the problem-based approach. This approach is applied to The Gaston Berger University in Saint-Louis.

Concerning problem-based learning in anatomy, teachers play a tutoring role by facilitating group discussions, guiding reflections and proposing work strategies. Unlike conventional teaching, specific anatomy textbooks are not recommended. Students learn through problem-based learning to use the library, anatomy classes, medical articles, websites and other available sources. The use of teaching aids during the preclinical curriculum allows students to realize the importance of anatomical knowledge. It also gives them the opportunity to practice in the diagnostic process. ${ }^{11,12}$

Reforming traditional anatomy by linking it to clinical practice has great benefits for learning. The application of anatomical principles in the explanation of clinical signs and therapeutic procedures enhances the motivation of students to learn anatomy., ${ }^{2,13,14}$ In a study conducted in the United States of America, ${ }^{15}$ the authors wanted to determine among students starting their residency the areas in which anatomical knowledge was most lacking. The area most concerned was the clinical application of anatomy. It appears from this work that for undergraduate medical students, the need for training in the practical approach to anatomy is very important. In this American study, students were positive about the fact that clinical case studies improve their understanding of anatomy. This trend has also been reported by our students in Saint-Louis. This confirms the idea that to study anatomy nothing stimulates a medical student better than the correlation between anatomy and their future medical practice.

Anatomy has always been recognized as one of the essential foundations of the clinical sciences. However, the effectiveness of anatomy teaching has been improved by introducing clinical problems 
into the basic sciences. Many medical students claim that knowledge acquired in the basic sciences during pre-clinical years fades when they reach clinical levels. ${ }^{16,17}$ Adequate knowledge of anatomy with special emphasis on clinical correlation is considered crucial for the healthy and effective practice of medicine. The pedagogical experience than we report is limited: it has been applied only once, and to less than 90 students. The results described reflect only the perception of the participants. However our educational experience shows that it is interesting to vary the teaching methods of anatomy, emphasizing the clinical aspects. In addition, further studies are needed to evaluate the long-term effectiveness of this new teaching method. It would be interesting to study the correlation between the introduction of problem-based learning in anatomy and the improvement of patient care.

\section{Conclusion}

In conclusion, our work shows that problem-based learning in anatomy can be a good teaching method, completing traditional teaching methods. Even among youngest medical students, problembased learning is an excellent approach to applied anatomy and clinical medicine.

\section{Acknowledgements}

None.

\section{Conflicts of interest}

The authors declare that they have no conflicts of interest regarding this study.

\section{References}

1. Percac S, Goodenough DA. Problem based teaching and learning as a bridge from basic anatomy to clinical clerkships. Surg Radiol Anat. 1998;20(3):203-207.

2. Boon JM, Meiring JH, Richards PA, et al. Evaluation of clinical relevance of problem-oriented teaching in undergraduate anatomy at the University of Pretoria. Surg Radiol Anat. 2001;23(1):57-60.

3. Albanese MA, Mitchell S. Problem-based learning: a review of literature on its outcomes and implementation issues. Acad Med. 1993;68(1):52-81.
4. Peplow PV. Self-directed learning in anatomy: incorporation of casebased studies into a conventional medical curriculum. Med Educ. 1990;24(5):426-432.

5. Scott TM. A case-based anatomy course. Med Educ. 1994;28(1):68-73.

6. Vernon DT, Blake RL. Does problem-based learning work? A metaanalysis of evaluative research. Acad Med. 1993;68(7):550-563.

7. Teichgraber UKM, Meyer JMA, Berens von Rautenfeld D. Teaching applied anatomy to senior medical students with an emphasis on surgery and radiology. Surg Radiol Anat. 1996;18(2):141-142.

8. Côté DJ, Graillon A, Waddell G, et al. L'approche d'apprentissage dans un curriculum médical préclinique basé sur l'apprentissage par problèmes. Pédagogie médicale. 2006;7(4):201-212.

9. Chakravarty M, Latif NA, Abu Hijleh MF, et al. Assessment of anatomy in a problem $\square$ based medical curriculum. Clin Anat. 2005;18(2):131-136.

10. Nendaz A, Tekian K. Assessment in problem-based learning medical schools: a literature review. Teach Learn. 1999;11(4):232-243.

11. Nasr MW, Yazigi A, Moussa R. Un problème pédagogique pour initier les étudiants en médecine à... l'apprentissage par problèmes. Pédagogie médicale. 2004;5(2):103-109.

12. Havet E, Duparc F, Peltier J, et al. The article critique as a problem-based teaching method for medical students early in their training: a French example using anatomy. Surg Radiol Anat. 2012;34(1):81-84.

13. Abu-Hijleh MF, Chakravarty M, Al Shboul Q, et al. Integrating applied anatomy in surgical clerkship in a problem-based learning curriculum. Surg Radiol Anat. 2005;27(2):152-157.

14. Ganguly KP, Chakravarty M, A-Latif N, et al. Teaching of anatomy in a problem-based curriculum at the Arabian Gulf University: the new face of the museum. Clin Anat. 2003;16(3):256-261.

15. Cottam WW. Adequacy of medical school gross anatomy education as perceived by certain postgraduate residency programs and anatomy course directors. Clin Anat. 1999;12(1):55-65.

16. Collins JP. Teaching and learning anatomy. Student BMJ 16. 2008.

17. Smith CF, Mathias HS. Medical students' approaches to learning anatomy: students' experiences and relations to the learning environment. Clin Anat. 2010;23(1):106-114. 